\title{
Research on Public Participation in Sustainable Urbanization Process
}

\author{
Hai $\mathrm{Hu}^{1}$ \\ ${ }^{1}$ College of Politics, Sichuan Agricultural University, China \\ Correspondence: Hai Hu, College of Politics, Sichuan Agricultural University, 46, Xinkang Road, Yucheng \\ District, Ya’an City 625014, China. Tel: 86-138-8243-0813. E-mail: huhai119@163.com
}

Received: April 20, 2012 Accepted: May 8, 2012 Online Published: June 1, 2012

doi:10.5539/jpl.v5n2p162 URL: http://dx.doi.org/10.5539/jpl.v5n2p162

\begin{abstract}
This paper argues that the problems emerging in the process of current Government-led urbanization are caused by the unbalanced game mechanism between state forces and social forces in nature. In future, the key for achieving the sustainability of Chinese urbanization process is to seek for the institutional balance between the state and the society. Therefore, it is necessary to include the public interests demands into the process of urban development to achieve the benign interaction between the state and the society, jointly promoting the sustainable urban development.
\end{abstract}

Keywords: China, sustainable urbanization, public participation

\section{Introduction}

It is undeniable that urbanization has a key effect on promoting China's economic growth, boosting domestic demands, and improving national competitiveness. In China, the urbanization process has always in strong Government-led colors all the time, which helps it achieve remarkable performances with fast development. However, in order to pursue the high efficiency of urbanization, the general public opinions are often excluded from the proposal of urban projects, the progress, and the final assessment. The welfare from China's urbanization does not benefit each individual involved, which in a sense betrays the fundamental theme of urbanization ------ people-oriented. The problems are caused in nature by the unbalanced game mechanism between state forces and social forces so that they are not irreconcilable. Therefore, to achieve the sustainability of urbanization process, the key is how to take the top-down state promotion and the bottom-up interests demands into the institutional track. The extensive and deep participation of the public in urban development process seems to be necessary. Then, is it practical for China in fast urbanization process introducing public participation? How to coordinate democracy and efficiency? How to achieve a benign interaction between state forces and social forces? Those are precisely the points in this paper.

\section{The Theoretical Basis and Practical Basis for Public Participation in Sustainable Urbanization Process}

\subsection{The Growth of Public Awareness of Civil Rights Provides Internal Motives for Public Participation}

With the fast development of China economy, the former unitary interest pattern is replaced with highly-differentiated social interest structure, and people's awareness of civil rights awakes. In fact, the degree of social interest differentiation is one of important indicators assessing the degree of social modernization. The high differentiation of social interest structure makes it necessary to build a game mechanism to balance the interest. All modern societies have high differentiation and effective integration of interests. According to the words of Huntington, the political unrest, to a great degree, was mainly caused by "the rapid social change, the entry of new social groups who were mobilized quickly, to political field, and the slow development of political institutions. (Samuel Phillips Huntington, 1988, pp59-78)" "The speed of social mobilization and expansion of political participation is higher and the speed of political organization and institutionalization is lower, which result in nothing but political unrest and disorder. (Samuel Phillips Huntington, 1988, pp4-5)” Currently, with continuously strengthening motivation for interest demands of the public in China and the shortage of balance game mechanism, fast and passive urbanization triggers a sense of separation of people from cities, which has become a hidden danger affecting social harmony. Therefore, in the urbanization process with multiple interest subjects, the Government efficiency and social fairness are two equally important principles of sustainable urbanization process. In short, with the awaking of people's awareness of civil rights, people more and more understand that the improvement of self welfare is inseparable from the benign operation and development of 
urban. People ask to be involved in the public fields that closely relate to their interests. Besides, they try their best to make the Government reflect and consider their interests in drafting urban development strategies. It provides the most realistic and reliable motives for public participation.

\subsection{The Potential Risks of Government-Led Urbanization Make Public Participation Necessary}

In China, the urbanization is led by the Government. The Government is the "maker of strategy, supplier of institution, implementer, and assessor of performances" of urbanization (Rong Gu, 2006). It can be said that the most significant advantage of Government-led urbanization is the great-leap- forward development. However, "the market failure and the emphasis on fairness provide the economic basis for the Government intervention, but it does not guarantee that such an intervention is beneficial to the society. Government failure may be as common as market failure.” Unfortunately, we cannot deny the fact that the Government-led urbanization does generate some social risks, e.g. the sacrifice of welfare of social members, the increase of social unfairness, and the excessive overuse of ecological environment. This urbanization mode is unsustainable. An urgent need is to reform the current urbanization mode, changing the single Government-led mode into a multi-subject cooperative mode, the top-down administrative mode into the combined top-down and bottom-up mode, building a cooperative partnership among the Government, social communities, social organizations, relevant experts, and public media in the urbanization process.

\section{Establish the Overall Efficiency-Oriented Framework for Public Participation}

To achieve the sustainability of urban development, it is necessary to introduce public participation, but what needs to be clear is that the fundamental purpose of public participation is to enlarge social benefits as well as guarantee public interests at the same time, and finally promote social harmony. Similarly, improper participation will bring about problems, just as what was said by Thomas: "The understanding of the necessity of citizen participation is only the understanding of the first part of challenges of citizen participation, and might be the simplest part. Even if public managers and policy planners accept the idea of necessity of citizen participation, they need to choose at what time, what frequency, in what way, to which degree, to accept citizen participation ...... The second challenge for citizen participation in front of managers is named as puzzle of public involvement. It needs to answer: when should the public managers accept citizen participation, and how to invite and attract citizens to participate? (John Clayton Thomas, 2005, pp10)" Obviously, it is a great challenge for the introduction of public participation achieving the development efficiency and social satisfaction at the same time. Therefore, we try to build an overall effectiveness-oriented framework for public participation to solve the "puzzle of public involvement".

\subsection{The Breadth of Public Participation in Sustainable Urbanization Process}

The breadth of public participation in sustainable urbanization process means the extensiveness of actual participators. It should be noted that although modern democracy requires that citizens have extensive rights of participating state and social affairs, "it is impossible, even for perfect democracy, to make all formal social members play a role in decision-making. (Carl Cohen, 1988, pp12)" Only to increase the number of participators would not improve the effectiveness of participation. Therefore, to introduce public participation in urban development, the first problem is to make sure who will take participation. Here, we need to define the interests groups involving in specific projects of urban development. Next we should confirm the actual interests existing between these groups and urban development projects, and these groups' intentions and demands. Only by fully understanding the state of relevant interests groups, can the design of objectives and directions be more appropriate.

\subsection{The Depth of Public Participation in Sustainable Urbanization Process}

The depth of public participation in sustainable urbanization process refers to the quality of public participation, i.e. to what degree do the public will and interests affect the urbanization process, which is determined by the nature of participation. From the point of view of the relationship of the state and the society in China, although public participation has the character of social democracy, the Government is the creator of institutional environment for public participation. In this sense, the depth of public participation depends on the interaction of state forces and social forces to a certain extent. Therefore, to introduce public participation into sustainable urbanization process is in nature a cooperation mode for the sate and the society. On one hand, it involves the reform of state powers. The Government should reasonably intervene in the urbanization process under the premise of following the basic laws of urbanization and improving social fairness. Besides, the Government should treat the increasing demands for public participation in urban development with more positive attitude and provide institutional channels for public participation. On the other hand, it involves the improvement of public participation capabilities. Improve the skills for public participation and promote the formation of rational 
participation by developing social organizations actively. Then, combine the top- down administrative consciousness and the bottom-up social growth together and form the institutional cooperation and benign interaction between the Government and the public, jointly promoting the sustainable, healthy, and coordinative urban development.

\subsection{The Effectiveness of Public Participation in Sustainable Urbanization Process}

The effectiveness of public participation in sustainable urbanization process is the actual benefits obtained by subjects in public participation process and the general effectiveness in the whole urbanization process. It mainly focuses on two aspects: the response degree of the Government to public opinions and the satisfaction degree of the public to Government behaviors. So, to enhance the effectiveness of public participation, the first is to emphasize "democracy" at the institutional level, i.e. the Government fully respects and focuses on the participation right of the public. Meanwhile, the public respect the authority of the Government and act under the legal framework. The second is to emphasize the "cooperation" at the level of participation mechanism, i.e. the legal establishment of urban development projects must win sufficient support from the public. Meanwhile, the participation right of the public must be legally authorized by the Government. In other words, achieve the organic unity relationship of the public and the Government: mutually restrained and authorized, being mutual independent and coordinative. Therefore, an introduction of public participation into sustainable urbanization process helps to protect public interests on one hand. On the other hand, it helps to improve the credibility of the Government, thus forming a benign interactive relationship between the state and the society, and ultimately promoting the social harmony.

Generally speaking, as for why we emphasize the public participation in sustainable urbanization process, the first is to prove the democracy orientation in China's urbanization process and the second is to emphasize that cooperation is the motivation mechanism and process for public participation in urban development. To achieve the sustainability of urban development, the core is to properly handle the democratic and cooperative relationship between the state power and the public forces, so as to "balance political interests and economic interests by democracy, guarantee stability and security by laws, and win acceptance and cooperation by authorization of rights (Weizhi Deng, 2000)."

\section{The General Line for Establishing Public Participation in Sustainable Urbanization Process}

\subsection{Establish the Strategic Management Concept for Urban Development}

At present, the Government-led urbanization wears a strong sense of projects or wills. In order to pursue high efficiency of urbanization, the proposals, progresses, and final assessments of urban projects are seldom based on public opinions and demands. Rapid urbanization process does not bring a general improvement of happiness for citizens, which will inevitably harm social harmony. Therefore, to achieve the sustainability of urbanization process, it is necessary to introduce the strategic management concept, i.e. "strategic management emphasizes on prediction instead of responsiveness, on the long run instead of the short run. By scientifically analyzing the external challenges and internal threats in front of urban development, avoid potential risks in the planning, construction, and operation of urban development and make the urban more positive but not passive in shaping the future. (Dajian Zhu, 2004, p66)" Therefore, to achieve the sustainability of urbanization, considering the complex environment for urbanization process the Government must overcome the short-sighted deviation and listen to different interest groups and absorb their demands and opinions, proposes the strategic vision and program with predictability, and transforms the projects or wills-driving urban development mode into the strategy-oriented one, ensuring the urbanization benefit everyone involved. Of course, to establish the strategic management of urbanization process not only needs the conscious of local government, but more important is to achieve the transformation of China's Government from the development-oriented type into the public service-oriented one.

\subsection{Promote the Disclosure of Government Information}

Only on the basis of fully and really understand the Government activities, can the public effectively participate state and social affair management. Although the Regulation of the People's Republic of China on the Disclosure of Government Information provides a legal guarantee for the public understanding Government activities, the selective disclosure of Government information limits the recognition and judgment of the public to certain extent, which is also one of reasons for the lack of mutual trust between the public and the Government. Therefore, whether from the perspective of public participation or from the perspective of enhancing the legitimacy of Government behaviors, we need to vigorously promote the disclosure of Government information. This requires not only the conscious of the Government department to enhance the disclosure of Government information, but also the improvement of legal liabilities for the Government disclosing information. Besides, we 
need to build a media coverage mechanism for urban development, using the amplifier effect of media to attract more attentions and supports, especially technical supports, for public participation in urban development projects, and achieving the harmonious urban development.

\subsection{Foster Modern Social Organizations and Promote the Formation of Social Forces}

Sustainable urbanization is not built on Government forces but on the voluntary cooperation of the state and social forces. To achieve the benign interaction between the state and the society, we not only need to reform at the state level, but also depend on the formation of an autonomous society and its supports. From the transformation of society in China, the development of modern social organization means the growth of social forces. Therefore, it is necessary to organize the scattered individuals by forming various social organizations, which can not only report the political and economic demands of members to the Government, but also coordinate different interest relationships and political relationships, becoming regular institutions for political dialogues. In addition, in the process of constructing the service-oriented Government in China, social organizations can bear some social functions unloaded by the Government, which will push forward the transformation of Government functions and reduce governance costs to a lowest point. In short, to foster social forces that cooperate with and complement the state, the core is to reform the relationship of the state and the society, which is also the basic element for the building of harmonious society.

However, the growth of social forces is not spontaneous but dependent on the development of market and state. What's more, the growth of social organizations in China needs the active promotion of state forces due to the inferiority of China's social forces. Therefore, we suggest that: firstly, the Government should accelerate the construction of legal system, give up former limits to the foundation of social organizations, and guarantees a nice institutional environment for social organizations' effective participation; secondly, the Government should strengthen the supports for social organizations in fields of capitals, policies, and technologies; thirdly, the Government should guide and help to set up a number of standard social organizations, in the hope of producing a demonstration effect. However, after the foundation, how do these social organizations coordinate with the Government and various interest groups and participate in the decision-making process in urban development? How to prevent the alienation of social organizations? How to deal with the internal relationships within social organizations? And so on. We need to give answers to these questions. In short, the growth of social forces in China is still in a long way.

\subsection{Build the Comprehensive Participation System for Public Participation in Sustainable Urbanization Process}

At present, some enterprises take full advantages of customers' capacities by customer participation, which benefits both enterprises and customers. The comprehensive customer participation mode and customer participation chain give useful inspirations for comprehensive public participation in sustainable urbanization process. Therefore, by referencing from the customer participation chain, we can build a comprehensive participation system for the public from four stages: the preparation stage: establish the urban development project by the Government ------ disclose the information ------ media reports; the participation stage: motivate and organize interest groups ------ discuss programs ------ establish the development strategy with a priority; the implementation stage: set up the coordinative organizations in implementation ------ specialized monitor -----reports on implementation effects; the assessment stage: establish the assessment-related groups ------ form relevant assessment system ------ build indicators for social satisfaction assessment.

In short, to achieve the sustainable urban development is a two-way "shaping" process. On one hand, it relates to the reform of state powers. By regulating the state powers by institutional construction and promoting urban development, we can make state powers more responsible for the public. On the other hand, it concerns the foster of social endogenous forces in China. By improving the participation capacities and levels of the public, we can ultimately achieve the benign interaction between the state and the society, and make them jointly promote the sustainability of urbanization process.

\section{References}

Carl Cohen. (1988). Democracy. Beijing: The Commercial Press. pp12.

Deng, Weizhi. (2000). A brief discussion of distribution of political resources. Xinhua Digest, 2.

Gu, Rong. (2006). Analysis on Government leading factors of Chinese urbanization. Modern Urban Research, 3.

John Clayton Thomas. (2005). Public Participation in Public Decisions: New Skills and Strategies for Public Managers. Beijing: China Renmin University Press. pp10.

Samuel Phillips Huntington. (1988). Political Order in Changing Societies. Beijing: Huaxia Publishing House. 
pp59-78, 4-5.

World Development Report (1997). The State in a Changing World. Beijing: China Financial \& Economic Publishing House. pp26.

Zhu, Dajian. (2004). Manage Urban Development: Exploration on Sustainable Urban Management Mode. Shanghai: Tongji University Press. pp66. 